\title{
Prospects for the Use of Additional Cooling System for the Oil-Immersed Transformers with Thermoelectric Transducers
}

\author{
Andrey V. Dmitriev ${ }^{1}$, Oksana S. Dmitrieva ${ }^{2}$ and IInur N. Madyshev ${ }^{2}$ \\ ${ }^{1}$ Department of Theoretical Bases of Heat Engineering, Kazan State Power Engineering University, 420066 Kazan, Russia \\ ${ }^{2}$ Department of Food Production Equipment, Kazan National Research Technological University, 420015 Kazan, Russia
}

\begin{abstract}
The main cause of the transformers failure when thermal overload, is the inter-turn short circuit inside of the winding. Therefore, the additional cooling system for the oil-immersed transformers developed, which are able to reduce the peak load and its uniform distribution throughout the operation time, due to the accumulation of cold hours corresponding to the minimum thermal load. Determined the dynamics of the ice covering on the cold surface of the thermoelectric transducer in the tank with a certain amount of water. The theoretical justification of the interaction of flows in the device presented.
\end{abstract}

\section{Introduction}

The oil-immersed transformers are the critical elements of electric power and electrical engineering facilities. Their reliability and occupational safety provides high quality of distributed electric energy [1]-[3]. Failure of power transformer results in a significant economic loss due to the disruption or interruption of the technological process of the industrial enterprises.

Modern cooling systems for the oil-immersed transformers do not provide a sufficiently efficient heat transfer from the winding insulations when significant short-term overloads. The result is a decrease of the service life and reliability of the transformer [4]. Therefore, as a rule, the main cause of the transformers failure when thermal overload, is the inter-turn short circuit inside of the winding [5].

In this regard, it is necessary to develop additional cooling system for the oil-immersed transformers, which are able to reduce the peak load and its uniform distribution throughout the operation time, due to the accumulation of cold hours corresponding to the minimum thermal load.

\section{Additional cooling system for the oil- immersed transformers}

An example of a constructive design of such system is the use of additional capacity, equipped with a cascade of semiconductor thermoelectric modules. Thermoelectric transducer is a thermoelectric refrigerator with seriesconnected semiconductors of $\mathrm{p}$ - and n-type, forming $\mathrm{p}-\mathrm{n}$ and n-p-transitions between ceramic plates. Each of such transitions includes a thermal contact with one of the two radiators. As a result, transition of electric current with a certain polarity forms the temperature differential/drop between two radiators of the module: one radiator works like a fridge, another one is heated and serves for the heat dissipation $[6,7]$.

The lower part of the oil tank of the oil-immersed transformer includes holdover battery (Figure 1), that is designed for additional water cooling of the power transformer from the inside of a tank. For easy assembly, disassembly when capital repairs, plugs, the inlet and outlet pipes of the tank are connected by means of the pipe coil using pipes and flanges. The thermoelectric modules are fixed to one of the tank walls. Their cold side is used for the heat-transfer process of the cooling fluid inside of the tank. The heat-removing ribs are fixed to the hot side of the thermoelectric modules for the thermal discharge.

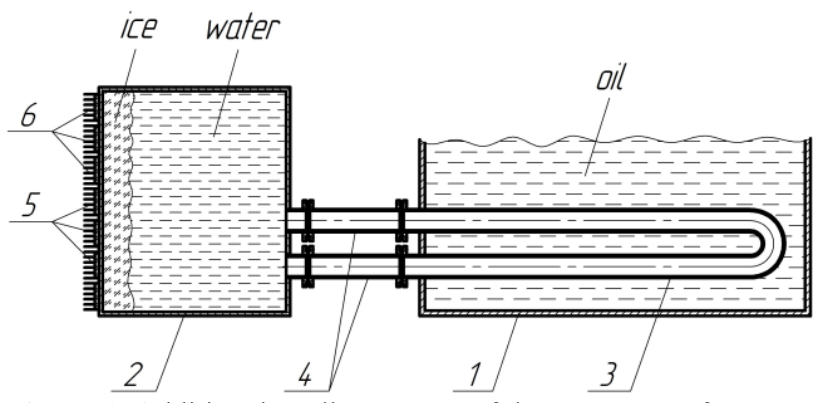

Figure 1. Additional cooling system of the power transformer: 1 - transformer tank; 2 - tank; 3 - pipe coil; 4 - communication pipes; 5 -thermoelectric modules; 6 - heat-removing ribs.

The additional cooling system for the oil-immersed transformers [8], developed by the authors of this article, works as follows. At low heat load, the coolant circulating through the pipe coil does not have time to reach high temperatures due to low heat transfer 
coefficients, characterizing the natural convection. Consequently, during the interval of the equipment's operational time, the cold accumulation in the tank takes place by means of thermoelectric modules. After a while on the cold side of the thermoelectric transducers, the ice forms a certain thickness. Further, with the heat load increase, which occurs mainly due to the high ambient temperatures, the pump (Figure 1 conventionally not shown) ensures forced circulation of the cooling fluid in the closed loop. The turbulence of the flow leads to higher heat transfer coefficient, thus increasing the natural circulation of the oil in the transformer tank, resulting in more effective cooling of the windings. Thus, additional liquid cooling of the bottom of the transformer tank increases the cooling efficiency of the transformer oil when maximum heat loads, preventing the failure of power transformers.

\section{Calculation procedure}

While design engineering process of the additional cooling systems for the oil-immersed transformers, an important task is the selection of the most efficient heat flow through the thermoelectric transducer and the selection of an optimal fluid volume, required for an adequate cooling of the power transformer in the hottest season - summer. Previously it was established that this time of a year the necessity of additional cooling for the oil-immersed transformer is about $50 \%$ of its work time per 24 hours that is about 12 hours. During this time, it is necessary to accumulate a sufficient amount of cold in the tank. In this case, as shown by the earlier numerical and experimental studies, the ice layer formation is possible on the cold side of the thermoelectric transducers 3-5 hours after shutdown of the pump, depending on the coolant temperature. The dynamic pattern of water temperature changes during this time interval can be determined by well known equations and is not of scientific interest. The greatest interest is the problem of determining the dynamics of the ice covering on the cold surface of the thermoelectric transducer in the tank with a certain amount of water.

In the studies include the assumption that heat is removed for the water cooling and its crystallization, that is, the ice formation:

$$
d Q_{\tau}=d Q_{\mathrm{b}}+d Q_{\mathrm{i}}
$$

The summands in the equation are determined by well known equations:

$$
\begin{gathered}
d Q_{\mathrm{b}}=m_{\mathrm{b}} c_{\mathrm{b}} d t_{\mathrm{b}}, \\
d Q_{\mathrm{i}}=r_{\mathrm{i}} d m_{\mathrm{l}},
\end{gathered}
$$

where $m_{\mathrm{b}}-$ water mass, $\mathrm{kg} ; m_{1}-$ ice mass, $\mathrm{kg} ; c_{\mathrm{b}}-$ mass specific heat of water, $\mathrm{J} /(\mathrm{kg} \cdot \mathrm{K}) ; r_{\mathrm{i}}$ - mass specific heat of crystallization, $\mathrm{J} / \mathrm{kg} ; d t_{\mathrm{b}}$ - water temperature change, $\mathrm{K}$.

The heat amount removed from the water can be determined as follows:

$$
d Q_{\mathrm{b}}=\alpha_{\mathrm{b}} F_{\mathrm{b}}\left(t_{\mathrm{b}}-t_{\mathrm{n}}\right) d \tau
$$

where $\alpha_{\mathrm{b}}$ - heat-transfer coefficient from water to the surface, $\mathrm{W} /\left(\mathrm{m}^{2} \cdot \mathrm{K}\right) ; t_{\mathrm{b}}$ - water temperature, $\mathrm{K} ; t_{\mathrm{n}}$ - surface temperature from the water side, $\mathrm{K} ; d \tau$ - time interval, s.

Equation (1) considering (3) and (4) can be transformed to:

$$
r_{\mathrm{i}} d m_{1}=d Q_{\tau}-\alpha_{\mathrm{b}} F_{\mathrm{b}}\left(t_{\mathrm{b}}-t_{\mathrm{n}}\right) d \tau .
$$

Considering the relationship of the heat quantity with the heat flow, we may record:

$$
r_{\mathrm{i}} d m_{\mathrm{l}}=Q d \tau-\alpha_{\mathrm{b}} F_{\mathrm{b}}\left(t_{\mathrm{b}}-t_{\mathrm{n}}\right) d \tau .
$$

Earlier, the authors obtained the dependence for the calculation of the heat transfer coefficient from water when the wall temperature is equal to $t_{\mathrm{n}}=273 \mathrm{~K}$ :

$$
\alpha_{\mathrm{b}}=13.518 t_{\mathrm{b}}^{1.827} / l^{0.248}
$$

where $l$ - length of the heat-transfer area, $\mathrm{m}$.

Considering this, we may record:

$$
r_{\mathrm{i}} d m_{\mathrm{l}}=\left(Q-13.518 t_{\mathrm{b}}{ }^{1.827} F_{\mathrm{b}} / l^{0.248}\right) d \tau .
$$

Equation (8) can be transformed to a form suitable for the calculation of temporal mass changes:

$$
d m_{1}=\left(1 / r_{\mathrm{i}}\right)\left(Q-13.518 t_{\mathrm{b}}{ }^{1.827} F_{\mathrm{b}} / l^{0.248}\right) d \tau .
$$

It should be noted that water temperature is a temporal changing parameter. Transforming the equation (2), we may record:

$$
d t_{\mathrm{b}}=\alpha_{\mathrm{b}} F_{\mathrm{b}} t_{\mathrm{b}} d \tau /\left(m_{\mathrm{b}} c_{\mathrm{b}}\right),
$$

which, taking into account the equation (7) may be recorded as follows:

$$
d t_{\mathrm{b}}=13.518 t_{\mathrm{b}}^{1.827} F_{\mathrm{b}} d \tau /\left(\left(m_{0}-m_{\mathrm{li}}\right) c_{\mathrm{b}} l^{0.248}\right) .
$$

Finally, to calculate the temporal changes of the ice mass and temperature, we can use the following dependencies:

$$
\begin{gathered}
m_{\mathrm{li}}=m_{\mathrm{li}-1}+\left(1 / r_{\mathrm{i}}\right)\left(Q-13.518 t_{\mathrm{b}}{ }^{1.827} F_{\mathrm{b}} / l^{0.248}\right) \Delta \tau, \\
t_{\mathrm{bi}}=t_{\mathrm{bi}-1}-13.518 t_{\mathrm{bi}-1}{ }^{1.827} F_{\mathrm{b}} \Delta \tau /\left(\left(m_{0}-m_{\mathrm{li}}\right) c_{\mathrm{b}} l^{0.248}\right) .
\end{gathered}
$$

The calculations were performed with different values of the heat flows through the thermoelectric transducer and the length of the heat-transfer area was $0.05 \mathrm{~m}$. The initial water temperature in the tank, at which the icing started, was changed from 4.5 to $8.5^{\circ} \mathrm{C}$, the water mass in the tank was estimated to be equal to $200 \mathrm{~kg}$. The area of water contact with the cooling surface was $1 \mathrm{~m}^{2}$. The results of numerical studies showed that the heat flow volume through the thermoelectric transducer affects the water cooling parameters and its crystallization only in the initial stage. Furthermore, it was found that all studied parameters, except the water temperature, do not depend on the length of the heat-transfer area.

\section{Results and discussion}

The Fig. 2 shows the water temperature temporal change in the tank, considering different values of the heat flow 
through the thermoelectric transducer. The diagram shows that the heat flow has a significant impact on the initial water temperature in the tank, at which the icing starts. For example, the 3 times increase of the heat flow through the thermoelectric transducer allows increasing the initial water temperature by 1.89 times. Relatively large changes are observed only in the first 3-4 hours of the thermoelectric transducer's operational time from the ice formation start. After that, the water temperature is almost independent of the heat flow values.

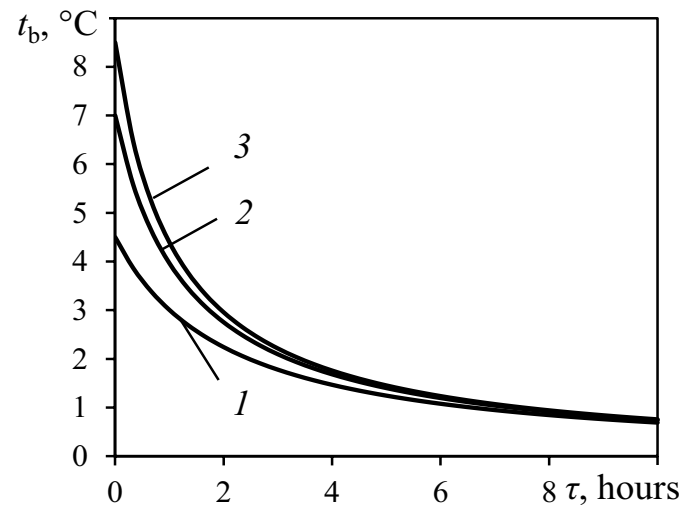

Figure 2. The water temperature temporal change in the tank, considering different values of the heat flow through the thermoelectric transducer, $Q$, W: $1-500,2-1000,3-1500$.

The heat-transfer coefficient from the water to the surface depends on the magnitude of the heat flow only at the initial stage of cooling and liquid crystallization (Figure 3). Then, the dependence disappears and the maximum change, when $\tau=4$ hours, is $16.23 \%$. The decrease of natural water convection in the tank, by reason of a substantial increase of its viscosity, results in the decrease of the heat-transfer coefficient.

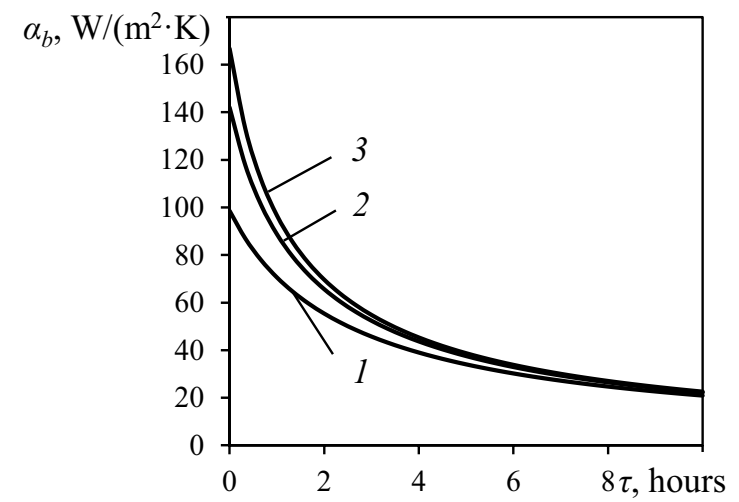

Figure 3. Temporal change of the heat-transfer coefficient from water to the surface, considering different values of the heat flow through the thermoelectric transducer, $Q$, W: $1-500,2-$ $1000,3-1500$.

Analyzing the diagram in Fig. 4, it can be concluded that the increase of the heat flow through the thermoelectric transducer leads to an almost proportional increase of the water fraction, converted to ice. For example, in 5 hours of the thermoelectric transducer's operational time, the increase of the heat flow by 3 times will provide the opportunity to achieve the ice share equal to 0.343 , that is, the increase will be by 3.35 times. It should be noted that the change of the water proportion, converted to ice, during the first 2 hours of operational time is characterized by power-law dependence, and in the future - linear.

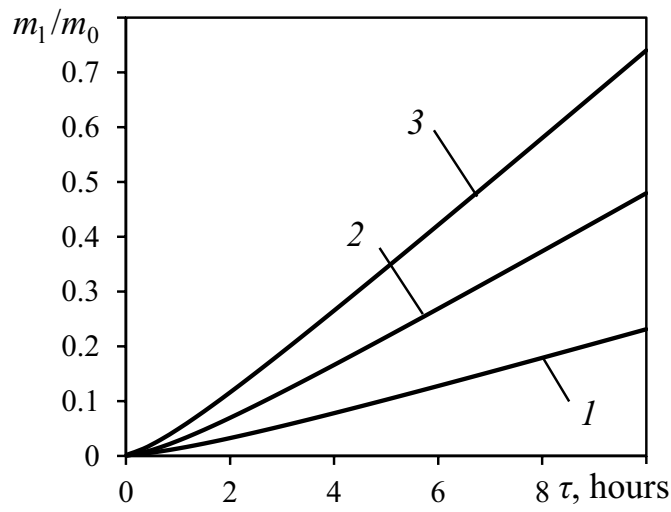

Figure 4. Temporal change of the water proportion, converted to ice, considering different values of the heat flow through the thermoelectric transducer, $Q, \mathrm{~W}: 1-500,2-1000,3-1500$.

The total thermal resistance increases almost in direct proportion to time (Figure 5). It is connected with the statement of the research problem, because the heat flow through the thermoelectric transducer remains constant.

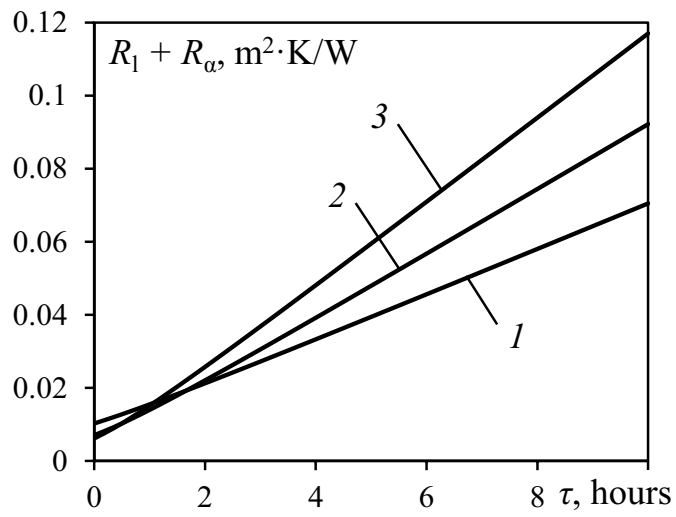

Figure 5. Temporal change of the total thermal resistance, considering different values of the heat flow through the thermoelectric transducer, $Q$, W: $1-500,2-1000,3-1500$.

The increase of the ice thickness leads to an increase of its thermal resistance (Figure 6).

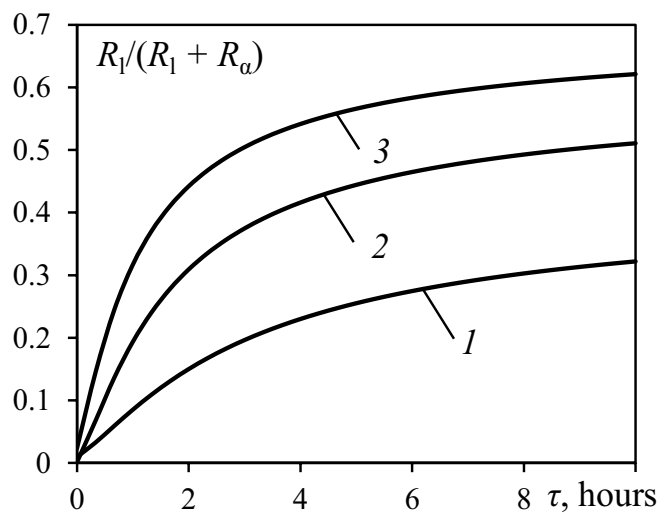

Figure 6. Temporal change of the impact of the thermal resistance of the ice layer on the total thermal resistance, considering different values of the heat flow through the thermoelectric transducer, $Q$, W: $1-500,2-1000,3-1500$. 
At the initial stage of cooling and the liquid crystallization, the thermal resistance of the ice layer provides rapid total thermal resistance. Further, when $\tau=$ 4 hours, there is a sharp decrease in the rate of change of this parameter. It should be noted that the higher heat flow through the thermoelectric transducer, the greater its thermal resistance (Figures 5, 6).

\section{Conclusion}

1. The numerical studies allow choosing the optimal heat flow through the thermoelectric transducer for cooling and liquid crystallization in the tank, based on the time for the cold accumulation. For example, for intensive cooling and water crystallization in a short period of time (within 3-4 hours), it is necessary to combine thermoelectric transducers with total heat flow of more than $1 \mathrm{~kW}$. If the prolonged liquid cooling at low heat loads is possible, it is sufficient to use thermoelectric transducer with a heat flow of $0.5 \mathrm{~kW}$.

2. The conducted research asserts that the use of the proposed additional cooling system for the oil-immersed transformers, by means of thermoelectric modules, allows to increase efficiency of their cooling when peak heat loads.

\section{Acknowledgments}

The reported study was funded by President of Russian Federation grant, according to the research project No. MK-5215.2016.8.

\section{References}

1. L. Kish, Heat and cooling of the transformers (Energy, Moscow, 1980). - 180 pp.

2. A.M. Golunov, N.S. Seshenko, The cooling devices for the oil-immersed transformers (Energy, Moscow, 1976). $-216 \mathrm{pp}$.

3. G. Gotter, Heat and cooling of the electrical machines (State Energy Press, Saint Petersburg, 1961). - $351 \mathrm{pp}$.

4. M.G. Bashirov, M.R. Minlibaev, A.S. Hismatullin, Cooling efficiency increase for the oil-immersed transformers, Neftegazovoe delo, 2, p. 347-357 (2014).

5. V.V. Sushkov, A.A. Zjabkin, Thermal processes modeling and diagnostics of power transformers of power supply systems of oil fields, Promyshlennaja jenergetika, 2, p. 39-42 (2013).

6. L.P. Bulat, Thermoelectric cooling: current state and trends, Holodil'naja tehnika, 8, p. 2-7 (2004).

7. O.S. Dmitrieva, A.V. Dmitriev, Cooling System for the oil-immersed transformer by means of thermoelectric modules, Izvestija vysshih uchebnyh zavedenij. Problemy jenergetiki, 11-12, p. 56-59 (2015).

8. A.V. Dmitriev, O.S. Dmitrieva, I.N. Madyshev, A.A. Sagdeev, A.N. Nikolaev, Zajavka na poleznuju model' № 2016112002 ot 30 marta 2016 goda. $A$ thermoelectric device for the additional cooling of oil transformer (Moscow, 2016) (to be published) 